\title{
Reference ranges for left, right and interventricular septum indices at 20 to 36+6 weeks of gestation derived using spectral myocardial tissue Doppler on Voluson ultrasound machines
}

\author{
Alberto Borges Peixoto ${ }^{1,2,3}$, Nathalie Jeanne Magioli Bravo-Valenzuela ${ }^{1}$, Wellington P. \\ Martins ${ }^{1,4}$, Rosiane Mattar ${ }^{1}$, Antonio Fernandes Moron' ${ }^{1}$, Edward Araujo Júnior ${ }^{1}$
}

Institutions: ${ }^{1}$ Department of Obstetrics, Paulista School of Medicine - Federal University of São Paulo (EPMUNIFESP), São Paulo, ${ }^{2}$ Mario Palmério University Hospital - University of Uberaba (UNIUBE), Uberaba, ${ }^{3}$ Department of Obstetrics and Gynecology, Federal University of Triângulo Mineiro (UFTM), Uberaba. ${ }^{4}$ SEMEAR Fertilidade, Reproductive Medicine, Ribeirão Preto, Brazil

\begin{abstract}
Aim: To establish reference range values for peak myocardial tissue Doppler velocity (MTD) and myocardial performance index (MPI) of the left ventricle (LV), the right ventricle (RV), and the interventricular septum (IVS) at 20 to $36+6$ weeks of gestation using spectral tissue Doppler. Material and methods: This cross-sectional study was conducted among 360 lowrisk singleton pregnancies. MTD during systole (S'), and early (E') and late diastole (A'), and MPI' were assessed by placing sample volume at the basal segment of the LV free wall, the RV free wall, and the IVS, respectively. Polynomial regression was used to obtain the best-fit curves for MTD and MPI' measurements as a function of gestational age (GA), and adjustments were made using the determination coefficient $\left(\mathrm{R}^{2}\right)$. Intra- and inter-observer reproducibility was evaluated using the concordance correlation coefficient (CCC). Results: All MTD velocities $(\mathrm{cm} / \mathrm{s})$ progressively increased with advancing GA ( $<0.0001)$. Mean LV MTD values were 4.19 to 6.86 for S', 3.52 to 7.22 for E', and 6.85 to 9.19 for A'; mean RV MTD were 4.85 to 7.97 for S', 4.49 to 8.66 for E', and 8.44 to 11.20 for A'; and mean IVS MTD values were 3.75 to 5.78 for S', 3.34 to 5.79 for E', and 5.88 to 7.98 for A'. LV MPI', RV MPI', and IVS MPI' did not significantly change with advancing GA. The CCC values for MTD were predominantly greater than 0.70 , while those for MPI' were $<0.70$. Conclusions: Reference values for the fetal MTD and MPI' of RV, LV and IVS using tissue Doppler between 20 and 36+6 weeks of gestation were described.

Keywords: cardiac function; tissue Doppler imaging; myocardial performance index; myocardial peak velocities; reference ranges
\end{abstract}

\section{Introduction}

New technologies in fetal echocardiography are being used increasingly as clinical and research tools to evaluate fetal cardiac function $[1,2]$. While conventional

Received 11.03.2019 Accepted 10.06.2019

Med Ultrason

2019, Vol. 21, No 3, 279-287

Corresponding author: Prof. Edward ARAUJO JÚNIOR, $\mathrm{PhD}$

Rua Belchior de Azevedo, 156 apto. 111

Torre Vitoria, São Paulo-SP, Brazil

CEP 05089-030

Phone/Fax: +55-11-37965944

E-mail: araujojred@terra.com.br echocardiographic techniques are based on blood flow, tissue Doppler imaging (TDI) is a preload-independent technique that allows direct measurement of regional myocardial velocities and duration of myocardial motion with greater accuracy [3-5]. TDI is a sensitive method of evaluating even mild impairments in systolic or diastolic function, and is therefore, useful for identifying subtle cardiac dysfunction in the preclinical stage [3].

Reference ranges for the peak myocardial tissue Doppler velocities (MTD) have been previously published for various populations using diverse equipment and settings [1,4-6], and recent data in adults have shown variations of up to $30 \%$ between the various ultrasound machines used for deriving these values [7]. Importantly, 
agreement among the various ultrasound systems is poor for fetal measurements with high coefficients of variation seen in all measurements [3]. Therefore, it is recommended that the fetal cardiac function be evaluated using the same equipment and settings in routine clinical practice.

The original technique used for measuring myocardial performance index (MPI) permitted simultaneous evaluation of systolic and diastolic cardiac function by capturing blood flow across the mitral valve inflow and aortic valve outflow [8] and was calculated as the following: isovolumetric contraction time (ICT) + isovolumetric relaxion time (IRT) / ejection time (ET) [8,9]. Although the use of aortic and mitral Doppler valve clicks as demarcations of time intervals has made the method more reliable and reproducible, differences in study methodology have contributed to wide variation in MPI values $[10,11]$. Furthermore, right ventricle (RV) MPI measurement is more difficult than left ventricle (LV) MPI, given the difficulty of simultaneously recording both inflow and outflow in a single Doppler sample. If the inflow and outflow Doppler signals are obtained separately, heart rate fluctuations may introduce errors and increase variability in measurement. An easier and alternative method of determining MPI for both ventricles is spectral tissue Doppler of the lateral free wall (mitral and tricuspid annulus), as it allows simultaneous recording of diastolic and systolic events in a single Doppler sample $[9,12]$. To the best of our knowledge, only one previously published study has established reference ranges for MPI' using spectral TDI [1].

Therefore, the aim of this study was to determine reference ranges for MTD and MPI', using spectral tissue Doppler, for the left ventricle (LV), the RV, and the interventricular septum (IVS) at 20 to $36+6$ weeks of gestation.

\section{Material and methods}

This was a prospective cross-sectional study conducted between November 2015 and October 2017 that randomly selected low-risk pregnant women who underwent routine ultrasound. The study protocol was approved by the Ethics Committee of Federal University of São Paulo (UNIFESP) and the Uberaba University (UNIUBE) (CAAE: 48421315.4.0000.5505).

The inclusion criteria were as follows: singleton pregnancies; body mass index $(\mathrm{BMI}) \leq 35 \mathrm{~kg} / \mathrm{m}^{2}$; gestational age (GA) between 20 and $36+6$ weeks determined by last menstrual period (LPM) and confirmed by ultrasound scan performed before 22 weeks with crown-rump length (CRL) corresponding to between 11 and 13+6 weeks, and biparietal diameter (BPD) to between 14 and 22 weeks; and normal cardiac structural evaluation according to guidelines issued by the International Society of Ultrasound in Obstetrics and Gynecology (ISUOG) and the American Institute of Ultrasound in Medicine (AIUM) $[13,14]$. All pregnant women were assessed only once.

The sample size was calculated according to Royston's precept [15], which recommends that to build reference range requiring $90 \%$ variance between the $5^{\text {th }}$ and the $95^{\text {th }}$ percentile, a sample of approximately 20 cases per stage of GA is recommended.

All ultrasound evaluations were performed in the Fetal Medicine Discipline of the Federal University of São Paulo (São Paulo-SP) and the Mário Palmério University Hospital (Uberaba-MG). All assessments were performed by the same person (ABP) using convex probes (RAB6-D, 2-8 MHz) of Voluson E6 and Voluson E8 (General Electric, Healthcare, Zipf, Austria) ultrasound machines. Absence of fetal movements with the mother in voluntary suspended respiration was also ensured during the ultrasound examination.

Data on the following variables were collected to analyze the demographic profile of the study population: maternal age, gestation number, parity, ethnicity, GA at the time of scan, weight, height, BMI, systolic blood pressure (SBP), diastolic blood pressure (DBP), last serum fasting glucose level during prenatal care, GA at delivery, mode of delivery, birth weight, Apgar scores at the $1^{\text {st }}$ and $5^{\text {th }}$ minutes, fetal death, neonatal death, type of delivery, and admission to the intensive care unit.

Two-dimensional (2D) ultrasound was used for fetal growth assessment, quantification of the amniotic fluid volume [16], morphological evaluation of the heart, and fetal weight estimation, according to guidelines proposed by Hadlock et al [17]. The birth weight estimation was performed according to the guidelines proposed by Nicolaides et al [18].

To obtain the tissue Doppler waveform, the fourchamber view of the fetal heart (apical or basal view) was magnified using a high-resolution zoom. 2D scan area was kept as small as possible to obtain the highest frame rate (64-127 frames/s). Doppler horizontal sweep speed was adjusted as $5 \mathrm{~cm} / \mathrm{s}$ to display four to six (but no more than 8 to 10) complete cardiac cycles. Gain was adjusted as $-25 \mathrm{~dB}$ in order to see clearly the Doppler velocity waveform, without the presence of artefacts in the background of the display. A sample volume, between 2 and $4 \mathrm{~mm}$, was placed at the level of the atrio-ventricular valves plane, in the basal part of the RV (tricuspid annulus), the LV (mitral annulus), and the IVS. The insonation ultrasound beam was maintained at an angle of $<30^{\circ}$ to the orientation of the ventricular wall or the IVS without 


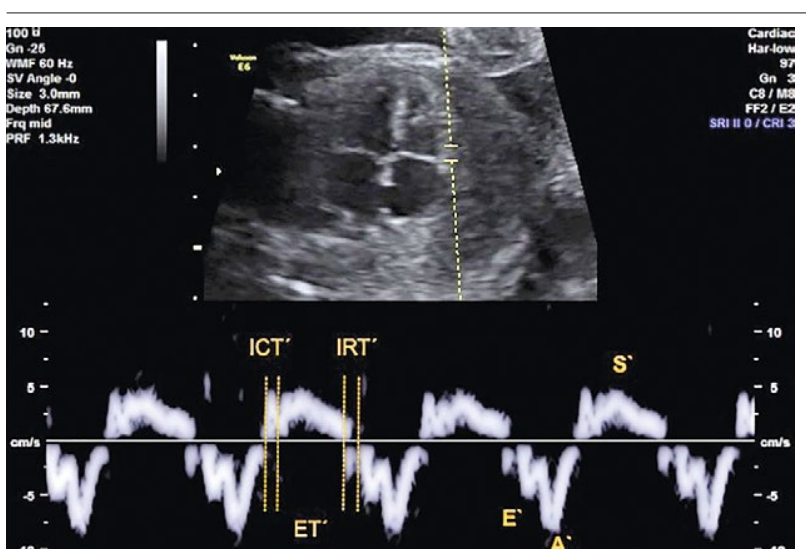

Fig 1. Myocardial tissue Doppler velocities (MTD) and myocardial performance index obtained by spectral tissue Doppler (MPI') of the right ventricle. E' wave (early diastolic annular peak velocity), A' wave (late-diastolic annular peak velocity) and S' wave (systolic annular peak velocity). MPI' = isovolumetric contraction time (ICT) + isovolumetric relaxation time (IRT') / ejection time (ET).

applying any correction angle [19]. Filter was set at 'low' (WMF $30-60 \mathrm{~Hz}$ ) to avoid high frequency signals and at least three Doppler waveforms were obtained for subsequent analysis (fig 1). One measurement was carried out for each individual fetus.

The left, right, and septal MPI' index was based on the measurement of isovolumetric contraction time (ICT'), isovolumetric relaxation time (IRT'), and ejection time (ET') and was defined as MPI'= ICT' + IRT'/ ET' $[20,21]$. In order to calculate manually MPI', the following periods were assessed from the same cardiac cycle: ICT' defined from the end of A' to the beginning of S', ET' from the beginning to the end of S', and IRT' from the end of S' to the beginning of E'. The Doppler waveform used to measure MPI' was also used to obtain MTD for RV, LV and IVS. MTD values were obtained for the E' wave (early diastolic annular peak velocity), the A' wave (late-diastolic annular peak velocity), and the S' wave (systolic annular peak velocity) [20,21].

\section{Statistical analysis}

All data were transferred to Excel spread sheets (Microsoft Corp., Redmond, WA, USA) and analyzed by one of the authors (WPM) using the PASW program (version 18.0, SPSS Inc., Chicago, IL, USA). Continuous variables are presented as mean \pm standard deviation (SD) and range. Categorical variables are presented as percentages. A polynomial regression model was used to obtain reference values for fetal cardiac function parameters, as recommended by Altman and Chitty [22]. Regression analysis was used to obtain a polynomial equation for the best-fit model for the measurements and their SD values as a function of GA. Percentiles for the measurements were calculated using the following formula: $=$ mean + $(\mathrm{SD} * \mathrm{~K})$, where $\mathrm{K}$ is the corresponding percentile of the standard normal distribution, i.e., \pm 1.65 for the $5^{\text {th }}$ and $95^{\text {th }}$ percentiles. The $5^{\text {th }}, 50^{\text {th }}$, and $95^{\text {th }}$ percentiles were determined for each GA as described earlier [22] along with the coefficient of determination $\left(\mathrm{R}^{2}\right)$ and the Pearson's correlation coefficient (r). These coefficients were used to evaluate, respectively, variation in parameters that were linearly related to GA and the strength of correlation between the variable and gestational age.

To estimate intra-observer reproducibility, the same examiner (ABP) performed a second set of measurements in 41 randomly selected cases. To test inter-observer reproducibility, a second examiner (NJBV) blindly performed the measurements of the same 41 cases shortly after the first examiner (ABP) exited the scan room. Reliability of intra and inter-observer measurements was established based on concordance correlation coefficient (CCC) values that used both absolute and relative differences between the values and their $95 \%$ confidence intervals (CI) [23]. To assess intra- and inter-observer reproducibility, limits of agreement (LoA) was used to determine the interval expected to contain $95 \%$ of the differences between measurements.

\section{Results}

MTD and MPI' and its respective time intervals, were obtained in 360 singleton pregnancies using spectral tissue Doppler. Clinical characteristics and pregnancy outcomes of the study population are shown in Table I.

Regression equations representing the relationship between variables studied and GA are shown in Table II. The best model for most parameters was a first-degree linear polynomial, with the exception for the RV E' wave, which was an exponential-degree polynomial equation. The values for the median, $5^{\text {th }}$ and $95^{\text {th }}$ percentiles at each GA stage for E' wave, A' wave, S' wave, MPI' and its respective time intervals of the RV, LV and IVS are provided as supplementary information (Tables SI-SXXIV, on the journal site).

The values for E' wave, A' wave, S' wave, E'/A' ratio of the RV, the LV, and the IVS progressively increased with GA (fig 2). ICTs' of both free wall ventricles and the IVS showed a significant increase with GA. ET' of the RV and the IVS also increased with advancing GA. In contrast, ET' of the LV and all measurements of IRT' and MPI' remained constant between 20 and $36+6$ weeks of gestation (fig 3). Despite an increase in some MPI' time intervals in the second and third trimester of pregnancy, based on $\mathrm{R}^{2}$ coefficient values, only a small proportion of their variation was attributable to GA. 
The mean GA of the patients included in the reproducibility analysis was 25.6 weeks (range $21-32$ weeks). Between 20 and 36+6 weeks, most intra-observer MTD measurements demonstrated a CCC value of $>0.70$; and were in contrast with most of the inter-observer measurements of MTD which showed CCC values of $<0.70$. The remaining intra- and inter-observer reproducibility values for MPI' of the IVS and both free wall ventricles, and their respective time intervals, demonstrated CCC values of $<0.70$, with the exception of ICT' of the RV (intra-observer CCC: 0.83 , inter-observer CCC: 0.80 ). The highest overall CCC values (0.86) were obtained for intra-observer RV-E' values, while the lowest overall CCCs (0.27) were seen with inter-observer ET'-RV values. Finally, Bland-Altman analysis demonstrated that the LoA for the results crossed zero for all measures, indicating no significant systematic bias between observers (Tables III and IV).

Table I. Demographic characteristics and pregnancy outcomes of the study population.

\begin{tabular}{|c|c|c|c|c|c|}
\hline & Median (range) & Mean (SD) & $\mathbf{n}$ & $\mathbf{N}$ & $\%$ \\
\hline Maternal age (years) & $27.0(14.0-44.0)$ & $27.7(7.1)$ & & & \\
\hline Gravida & $2.0(1.0-12.0)$ & $2.2(1.4)$ & & & \\
\hline Parity & $1.0(0.0-10.0)$ & $0.8(1.1)$ & & & \\
\hline Gestational age (weeks) & $27.9(20.0-37.0)$ & $27.8(4.9)$ & & & \\
\hline Weight (kg) & $68.0(41.0-93.9)$ & $67.9(10.5)$ & & & \\
\hline Height (m) & $1.6(1.4-1.8)$ & $1.6(0.1)$ & & & \\
\hline BMI $\left(\mathrm{kg} / \mathrm{m}^{2}\right)$ & $25.9(16.6-34.9)$ & $26.1(3.8)$ & & & \\
\hline $\mathrm{SBP}(\mathrm{mmHg})$ & $110.0(80.0-150.0)$ & $107.6(10.1)$ & & & \\
\hline $\mathrm{DBP}(\mathrm{mmHg})$ & $60.0(50.0-90.0)$ & $66.1(7.6)$ & & & \\
\hline Fasting Glucose (mg/dl) & $79.0(50.0-91.0)$ & $78.5(6.8)$ & & & \\
\hline $\mathrm{HC}(\mathrm{mm})$ & $251.1(158.7-342.4)$ & $249.0(48.1)$ & & & \\
\hline $\mathrm{AC}(\mathrm{mm})$ & $226.5(129.1-342.4)$ & $229.0(53.1)$ & & & \\
\hline $\mathrm{FL}(\mathrm{mm})$ & $50.3(14.6-71.3)$ & $49.8(11.3)$ & & & \\
\hline $\mathrm{EFW}(\mathrm{g})$ & $1148(307-3394.0)$ & $1275.2(774.4)$ & & & \\
\hline EFW (centile) & $37(10-92)$ & $38.2(18.4)$ & & & \\
\hline $\operatorname{MVDP}(\mathrm{cm})$ & $4.7(2.2-8.5)$ & $4.7(1.1)$ & & & \\
\hline FHR (bpm) & $142(110-168)$ & $142,2(9.6)$ & & & \\
\hline GA at delivery (weeks) & $39.2(32.0-42.0)$ & $39.0(1.5)$ & & & \\
\hline Birth weight (grams) & $3210(1675-4480)$ & $3238.3(430.5)$ & & & \\
\hline Birth weight (centile) & $39.0(5-99)$ & $43.3(26.5)$ & & & \\
\hline Apgar score 1st min & $9.0(0.0-10.0)$ & $8.3(1.4)$ & & & \\
\hline Apgar score 5 th $\min$ & $9.0(0.0-10.0)$ & $9.2(0.9)$ & & & \\
\hline \multicolumn{6}{|l|}{ Ethnicity } \\
\hline White & & & 192 & 360 & 53.3 \\
\hline Black & & & 55 & 360 & 15.3 \\
\hline East Asia & & & 5 & 360 & 1.4 \\
\hline Other & & & 108 & 360 & 30 \\
\hline \multicolumn{6}{|l|}{ Mode of delivery } \\
\hline Vaginal & & & 120 & 302 & 39.7 \\
\hline Cesarean section & & & 181 & 302 & 59.9 \\
\hline Forceps & & & 1 & 302 & 0.3 \\
\hline Fetal death & & & 1 & 302 & 0.3 \\
\hline Neonatal death & & & 1 & 302 & 0.3 \\
\hline Neonatal IUC & & & 12 & 302 & 4 \\
\hline
\end{tabular}

$\mathrm{N}$ : number of population studied, n: number of cases, AC: abdominal circumference, BMI: body mass index, DBP: diastolic blood pressure, EFW: estimated fetal weight, FHR: fetal heart rate, FL: femur length, GA: gestational age, HC: head circumference, IUC: intensive unit care, MVDP: measure of the vertical deepest pocket, SBP: systolic blood pressure, SD: standard deviation. 
Med Ultrason 2019; 21(3): 279-287 283
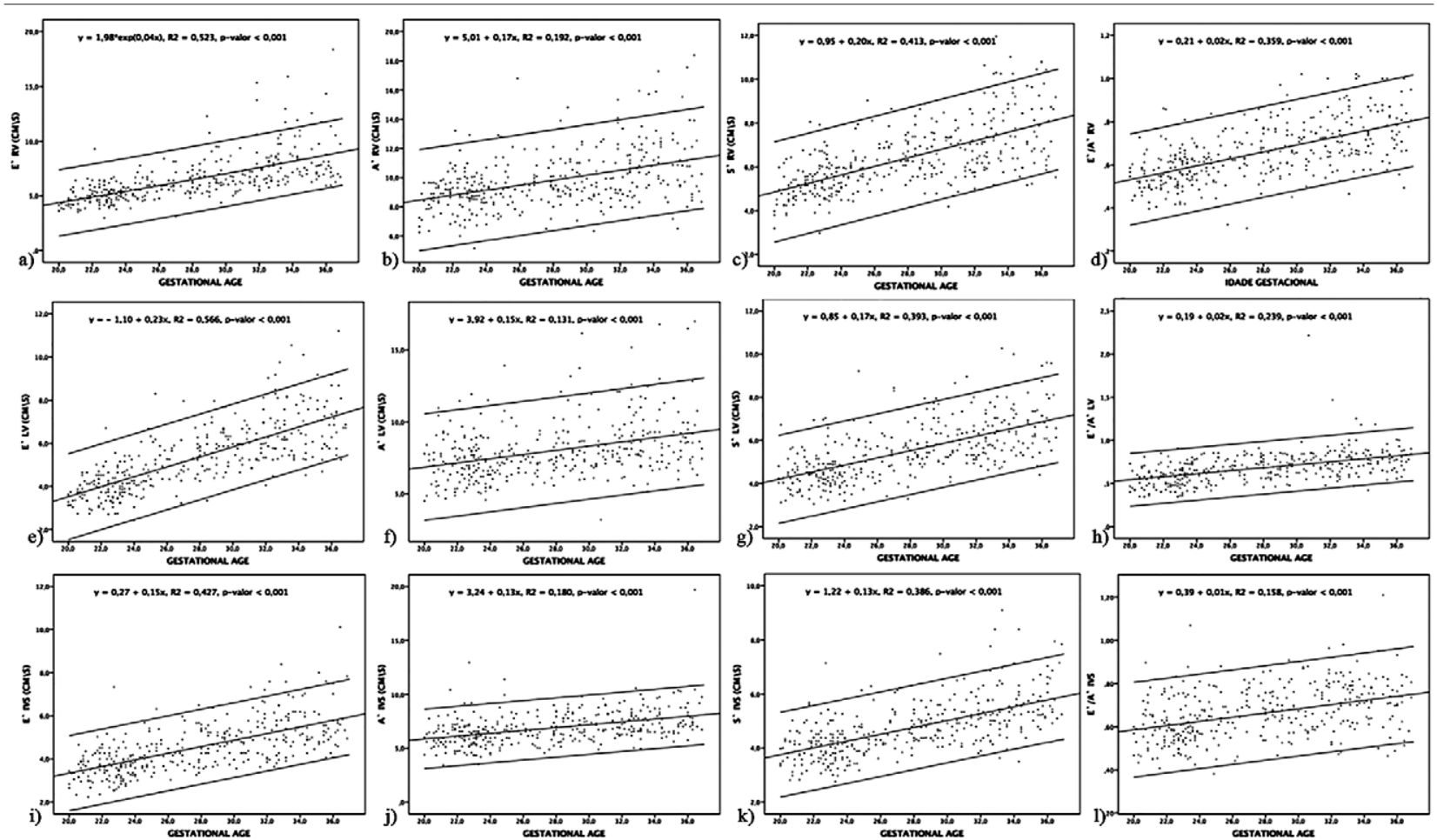

Fig 2. Scatter plots of E' wave (early diastolic annular peak velocity), A' wave (late-diastolic annular peak velocity), S' wave (systolic annular peak velocity), and E'/A' ratio of the right ventricle (RV) (a-d), left ventricle (LV) (e-h) and interventricular septum (IVS) (i-1) plotted against GA (weeks) in the study population. Estimated $5^{\text {th }}, 50^{\text {th }}$ and $95^{\text {th }}$ percentile curves are shown.
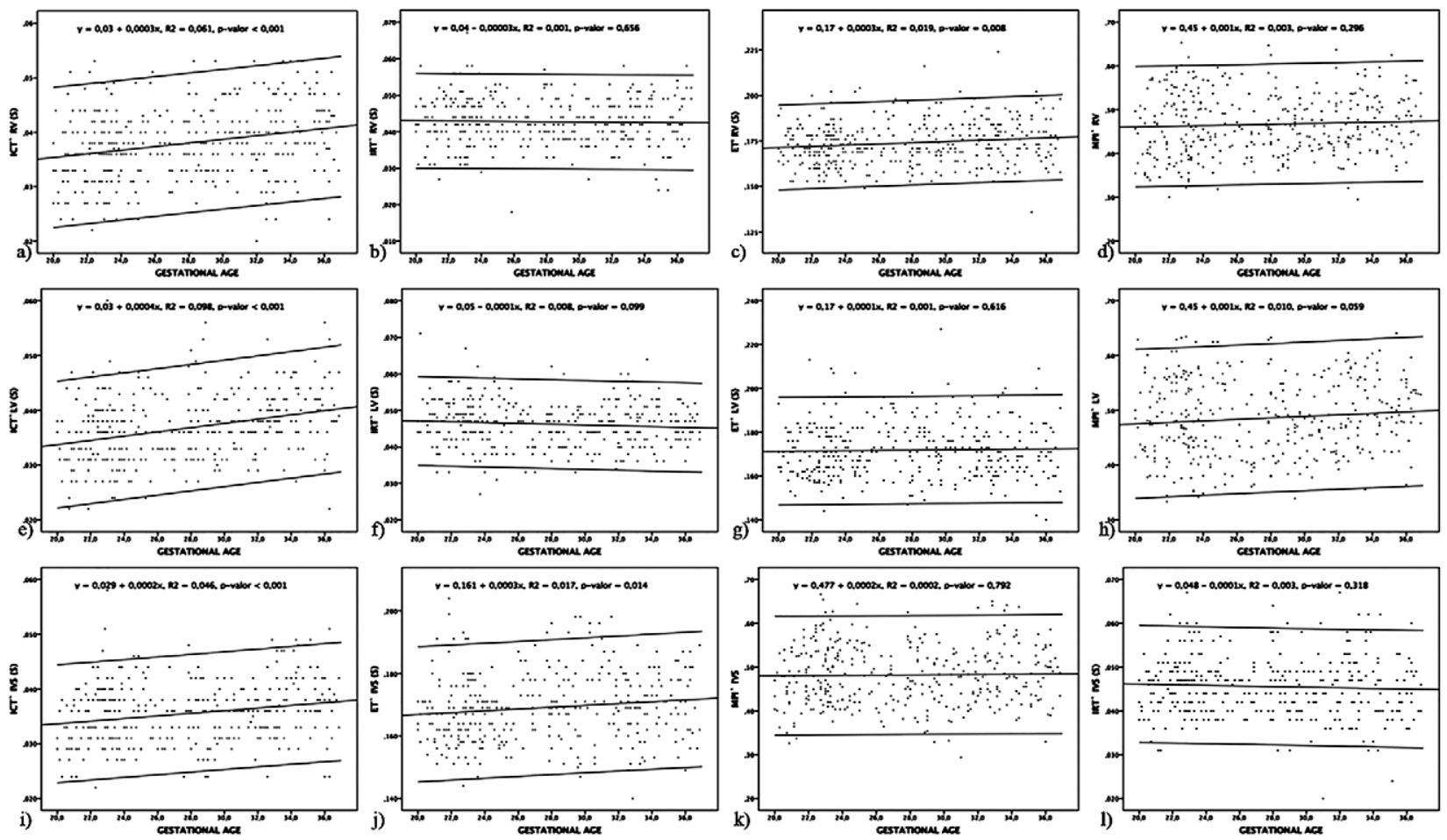

Fig 3. Scatter plots of isovolumetric contraction time (ICT'), isovolumetric relaxation time (IRT'), ejection time (ET'), and myocardial performance index using spectral tissue Doppler of the right ventricle (RV) (a-d), left ventricle (LV) (e-h), and interventricular septum (IVS) (i-1) plotted against GA (weeks) in the study population. Estimated $5^{\text {th }}, 50^{\text {th }}$ and $95^{\text {th }}$ percentile curves are shown. 
Table II. Regression equations for cardiovascular parameters obtained by tissue Doppler imaging.

\begin{tabular}{|c|c|c|c|c|}
\hline Parameter & Mean & $\mathbf{r}$ & $\overline{\mathbf{R}^{2}}$ & $\mathbf{p}$ \\
\hline $\begin{array}{l}\text { E'RV } \\
(\mathrm{cm} / \mathrm{s})\end{array}$ & $\mathrm{y}=1.975 \times \mathrm{e}^{0.041 \times \mathrm{xA}}$ & 0.723 & 0.723 & 0.523 \\
\hline $\begin{array}{l}\text { A' RV }^{\prime} \\
(\mathrm{cm} / \mathrm{s})\end{array}$ & $y=5.010+0.172 x G A$ & 0.438 & 0.438 & 0.192 \\
\hline $\begin{array}{l}S^{\prime} \text { RV } \\
(\mathrm{cm} / \mathrm{s})\end{array}$ & $y=0.951+0.195 x G A$ & 0.642 & 0.642 & 0.413 \\
\hline E'/A'RV & $\mathrm{y}=0.210+0.016 \mathrm{xGA}$ & 0.6 & 0.6 & 0.359 \\
\hline $\begin{array}{l}\text { ICT' RV } \\
\text { (s) }\end{array}$ & $\mathrm{y}=0.029+0.0003 \times \mathrm{xGA}$ & 0.247 & 0.247 & 0.061 \\
\hline $\begin{array}{l}\text { IRT' RV } \\
\text { (s) }\end{array}$ & $y=0.044-0.00003 x G A$ & 0.024 & 0.024 & 0.001 \\
\hline $\begin{array}{l}\mathrm{ET}^{\prime} \mathrm{RV} \\
(\mathrm{s})\end{array}$ & $y=0.165+0.0003 x G A$ & 0.139 & 0.139 & 0.019 \\
\hline $\begin{array}{l}\text { MPI' RV } \\
\text { (s) }\end{array}$ & $\mathrm{y}=0.446+0.001 \mathrm{xGA}$ & 0.055 & 0.055 & 0.003 \\
\hline $\begin{array}{l}E^{\prime} L V \\
(\mathrm{~cm} / \mathrm{s})\end{array}$ & $y=-1.100+0.231 x G A$ & 0.752 & 0.752 & 0.566 \\
\hline $\begin{array}{l}A^{\prime} L V \\
(\mathrm{~cm} / \mathrm{s})\end{array}$ & $\mathrm{y}=3.922+0.146 \mathrm{xGA}$ & 0.362 & 0.362 & 0.131 \\
\hline $\begin{array}{l}S^{\prime} L V \\
(\mathrm{~cm} / \mathrm{s})\end{array}$ & $\mathrm{y}=0.851+0.167 \mathrm{xGA}$ & 0.627 & 0.627 & 0.393 \\
\hline E'/A`LV & $\mathrm{y}=0.193+0.017 \mathrm{xGA}$ & 0.489 & 0.489 & 0.239 \\
\hline $\begin{array}{l}\text { ICT' LV } \\
\text { (s) }\end{array}$ & $\mathrm{y}=0.026+0.0004 \mathrm{xGA}$ & 0.313 & 0.313 & 0.098 \\
\hline $\begin{array}{l}\text { IRT' LV } \\
\text { (s) }\end{array}$ & $y=0.049-0.0001 x G A$ & 0.087 & 0.087 & 0.008 \\
\hline $\begin{array}{l}\text { ET' LV } \\
\text { (s) }\end{array}$ & $\mathrm{y}=0.170+0.0001 \mathrm{xGA}$ & 0.027 & 0.027 & 0.001 \\
\hline $\begin{array}{l}\text { MPI' LV } \\
\text { (s) }\end{array}$ & $\mathrm{y}=0.448+0.001 \mathrm{xGA}$ & 0.099 & 0.099 & 0.01 \\
\hline $\begin{array}{l}E^{\prime} \text { IVS } \\
(\mathrm{cm} / \mathrm{s})\end{array}$ & $y=0.27+0.15 x G A$ & 0.653 & 0.653 & 0.427 \\
\hline $\begin{array}{l}\text { A' IVS }^{\prime}(\mathrm{cm} / \mathrm{s})\end{array}$ & $y=3.24+0.13 x G A$ & 0.424 & 0.424 & 0.18 \\
\hline $\begin{array}{l}S^{\prime} \text { IVS } \\
(\mathrm{cm} / \mathrm{s})\end{array}$ & $\mathrm{y}=1.22+0.13 \mathrm{xGA}$ & 0.621 & 0.621 & 0.386 \\
\hline $\begin{array}{l}\text { E'/A' IVS } \\
(\mathrm{cm} / \mathrm{s})\end{array}$ & $\mathrm{y}=0.38+0.01 \mathrm{xGA}$ & 0.398 & 0.398 & 0.158 \\
\hline $\begin{array}{l}\text { ICT' IVS } \\
\text { (s) }\end{array}$ & $\mathrm{y}=0.029+0.0002 \mathrm{xGA}$ & 0.213 & 0.213 & 0.046 \\
\hline $\begin{array}{l}\text { IRT' IVS } \\
\text { (s) }\end{array}$ & $\mathrm{y}=0.048-0.0001 \mathrm{xGA}$ & 0.053 & 0.053 & 0.003 \\
\hline $\begin{array}{l}\text { ET' IVS } \\
\text { (s) }\end{array}$ & $\mathrm{y}=0.161+0.0003 \times \mathrm{xGA}$ & 0.13 & 0.13 & 0.017 \\
\hline $\begin{array}{l}\text { MPI' IVS } \\
\text { (s) }\end{array}$ & $\mathrm{y}=0.477+0.0002 \mathrm{xGA}$ & 0.014 & 0.014 & 0.0002 \\
\hline
\end{tabular}

A': late diastolic annular peak velocity, E': early diastolic annular peak velocity,E'/A': early diastolic annular peak velocity / late-diastolic annular peak velocity ratio, ET': ejection time using spectral tissue Doppler, GA: gestational age, ICT': isovolumetric contraction time using spectral tissue Doppler, IRT': isovolumetric relation time using spectral tissue Doppler, IVS: interventricular septum, LV: left ventricle, MPI': myocardial performance index (MPI') using spectral tissue Doppler, RV: right ventricle,S': systolic annular peak velocity.

\section{Discussions}

The number of publications addressing cardiac parameters in fetal medicine that use TDI, including MTD and MPI', to analyze fetal myocardial function has been increasing, because these parameters can detect myocardial dysfunction in the preclinical stages [2]. Therefore, establishing reference range values for TDI parameters may be useful for both research and in clinical practice. Here, we have provided reference ranges for MTD, MPI' and its respective time intervals for both ventricles and the IVS for 20 to $36+6$ weeks of gestation.

The reference values for the MTD of the E', A' and S' waves reported here are in agreement with those reported by previous studies [1,4-6]. A strong positive correlation was observed between GA and the E' and S' waves for $\mathrm{LV}, \mathrm{RV}$, and IVS. We also observed a moderate positive correlation between GA and A' wave of the RV and the IVS, between GA and E'/A' ratio for the RV and the LV, and a weak positive correlation between GA and E'/A' and with A' wave for LV. Chan et al [4] demonstrated a significant increase in MTD of the E', A' and S' waves of the $\mathrm{RV}$ and $\mathrm{LV}$, and in the E'/A' ratio with advancing GA. Similar results were reported by Comas et al [1], even after adjusting myocardial velocity peak values of the RV and LV for fetal weight. Gardner et al [24] demonstrated a positive correlation between all RV and LV MTD parameters and GA, except for the LV A' wave.

The RV MTD values were higher than those of the LV free wall and the IVS, emphasizing the dominance of the $\mathrm{RV}$ in fetal circulation [5], and it is known that the RV contribution is $30 \%$ greater than that of the LV in combined cardiac output [25]. This phenomenon is attributed to the preferential flow of systemic venous blood to the tricuspid valve, superior RV relaxation and compliance characteristics of the RV, and increased atrial contractility due to a higher load, based on the Starling mechanism [5].

We found good-to-moderate intra-observer agreement for MTD of RV, LV and IVS with CCC values above 0.70 for most comparisons. Although we used identical equipment (Voluson E6 and E8) in the study, CCC values were $<0.70$ for some MTD values. It is possible that fetal movements and position, high fetal heart rate, small fetal heart size, and restricted physical access to the fetus limited reproducibility [20]. Halpern et al [7] reported a variation of up to $30 \%$ between measurements of MTD when using different ultrasound equipment in adults. Cruz-Lemini et al [3] show that, in fetuses, agreement among MTD values obtained using two different ultrasound equipment (Vivid Q and Siemens Antares) was low with a high coefficient of variation (S' LV 25\%, E' LV 26\%, A' RV, S' RV 22\%, E' RV 24\% and A' RV 
Med Ultrason 2019; 21(3): 279-287 285

Table III. Concordance correlation coefficient (CCC) values and respective 95\% confidence intervals (CI) and limits of agreement (LoA) for intra- and inter-observer reproducibility of myocardial tissue Doppler velocities (MTD).

\begin{tabular}{|c|c|c|c|c|c|c|c|c|c|}
\hline \multirow{3}{*}{ Intra-observer } & \multirow[b]{2}{*}{$\mathrm{CCC}$} & & & \multicolumn{3}{|c|}{ Relative difference } & \multicolumn{3}{|c|}{ Absolute difference } \\
\hline & & \multicolumn{2}{|c|}{$95 \% \mathrm{CI}$} & Bias & \multicolumn{2}{|c|}{$L o A$} & Bias & \multicolumn{2}{|c|}{$\operatorname{LoA}$} \\
\hline & & & & & & & & & \\
\hline E’ RV & 0.86 & 0.76 & 0.92 & -0.8 & -21.6 & 20.0 & -0.05 & -1.31 & 1.21 \\
\hline$A^{\prime} \mathrm{RV}$ & 0.79 & 0.64 & 0.88 & 0.0 & -20.0 & 20.0 & -0.01 & -1.78 & 1.76 \\
\hline$S^{\prime}$ RV & 0.79 & 0.65 & 0.88 & -1.2 & -25.2 & 22.9 & -0.03 & -1.46 & 1.39 \\
\hline E'/A'RV & 0.71 & 0.51 & 0.83 & -1.0 & -26.7 & 24.7 & -0.01 & -0.17 & 0.16 \\
\hline$E^{\prime} L V$ & 0.76 & 0.59 & 0.86 & -0.3 & -29.8 & 29.1 & 1.1 & -28.9 & 31.1 \\
\hline$A^{\prime} L V$ & 0.68 & 0.48 & 0.82 & 1.1 & -27.7 & 29.9 & 2.5 & -35.7 & 40.7 \\
\hline S' LV & 0.72 & 0.54 & 0.84 & 3.5 & -24.3 & 31.4 & 5.9 & -30.0 & 41.7 \\
\hline E'/A'LV & 0.80 & 0.65 & 0.89 & -1.2 & -26.9 & 24.5 & -1.3 & -37.3 & 34.8 \\
\hline E'IVS & 0.76 & 0.59 & 0.86 & -1.6 & -27.9 & 24.6 & 0.0 & -1.14 & 1.07 \\
\hline A' IVS & 0.72 & 0.54 & 0.84 & -2.7 & -28.7 & 23.4 & -0.2 & -1.87 & 1.54 \\
\hline S'IVS & 0.68 & 0.49 & 0.81 & -2.7 & -24.0 & 18.7 & -0.1 & -0.96 & 0.78 \\
\hline E'/A'IVS & 0.63 & 0.40 & 0.78 & 1.0 & -30.8 & 32.8 & 0.0 & -0.19 & 0.20 \\
\hline \multicolumn{10}{|c|}{ Inter-observer } \\
\hline$E^{\prime} R V$ & 0.70 & 0.51 & 0.82 & 5.4 & -27.0 & 37.8 & 0.28 & -1.52 & 2.08 \\
\hline$A^{\prime} \mathrm{RV}$ & 0.72 & 0.53 & 0.84 & 2.6 & -21.6 & 26.8 & 0.21 & -1.89 & 2.32 \\
\hline$S^{\prime}$ RV & 0.67 & 0.47 & 0.80 & 2.7 & -28.7 & 34.1 & 0.19 & -1.58 & 1.95 \\
\hline E'/A'RV & 0.49 & 0.22 & 0.69 & 2.5 & -31.0 & 36.0 & 0.02 & -0.19 & 0.22 \\
\hline E'LV & 0.78 & 0.63 & 0.88 & -0.02 & -1.48 & 1.44 & 0.05 & -1.30 & 1.40 \\
\hline$A^{\prime} L V$ & 0.44 & 0.17 & 0.66 & 0.10 & -2.03 & 2.23 & 0.21 & -2.63 & 3.04 \\
\hline$S^{\prime} L V$ & 0.56 & 0.32 & 0.73 & 0.20 & -1.17 & 1.56 & 0.31 & -1.39 & 2.02 \\
\hline E'/A'LV & 0.59 & 0.34 & 0.76 & -0.01 & -0.16 & 0.14 & -0.01 & -0.23 & 0.21 \\
\hline E'IVS & 0.67 & 0.48 & 0.80 & 0.6 & -29.4 & 30.6 & 0.1 & -1.14 & 1.27 \\
\hline A' IVS & 0.52 & 0.26 & 0.70 & -1.7 & -33.6 & 30.2 & -0.1 & -2.01 & 1.89 \\
\hline S'IVS & 0.48 & 0.21 & 0.68 & -2.1 & -34.2 & 30.0 & -0.1 & -1.41 & 1.23 \\
\hline E'/A'IVS & 0.59 & 0.36 & 0.75 & 2.3 & -26.8 & 31.3 & 0.0 & -0.17 & 0.21 \\
\hline
\end{tabular}

A': late diastolic annular peak velocity, E': early diastolic annular peak velocity, E'/A': early diastolic annular peak velocity / late-diastolic annular peak velocity ratio, IVS: interventricular septum, LV: left ventricle, RV: right ventricle, S': systolic annular peak velocity.

$23 \%$ ). We did not evaluate variability between the two Voluson machines because they used the same platform. These observations imply that, in clinical practice, appropriate reference curves for each equipment may be necessary, and that comparison of MTD measures among studies may be difficult due to such variability among equipment.

To the best of our knowledge, this is only the second study to determine the reference range for MPI' of RV, LV and IVS using spectral tissue Doppler. While we show that LV MPI' values did not change with GA, Comas et al [1] have demonstrated a significant increase in LV MPI' between 24 and 41 weeks of gestation, although only $0.03 \%$ of their variation could be explained by growth-related changes of advancing GA. Additionally, they showed that RV and IVS MPI' remained constant with advancing GA and we also show no significant change in the RV and IVS MPI' values. However, the mean MPI'values for LV ( 0.490 vs. 0.510 , respectively), RV ( 0.460 vs. 0.490 , respectively) and IVS ( 0.480 vs. 0.510 , respectively) were lower than that reported by the previous study [1]. We also report reference values for MPI' time intervals; Comas et al [1] have not reported these values. Although the ICT' of the RV, ET' of the RV, ICT' of the LV, ICT' of the IVS and ET' of the IVS showed a significant increase with GA, only $6.1 \%, 1.9 \%$, $9.8 \%, 4.6 \%$ and $1.7 \%$ of their variation, respectively, was related to GA.

Bui et al [9] have demonstrated that the MPI' of the RV had a lower variability than conventional spectral MPI of the RV in normal fetuses. These authors also observed that for intra- and inter-observer evaluation, mean error percentage between measurements was $10 \%$ and $21 \%$, respectively. In partial disagreement with the Bui 
Table IV. Concordance correlation coefficient (CCC) values and respective $95 \%$ confidence intervals (CI) and limits of agreement (LoA) for intra- and inter-observer reproducibility of myocardial performance index using tissue Doppler (MPI') and its respective time intervals.

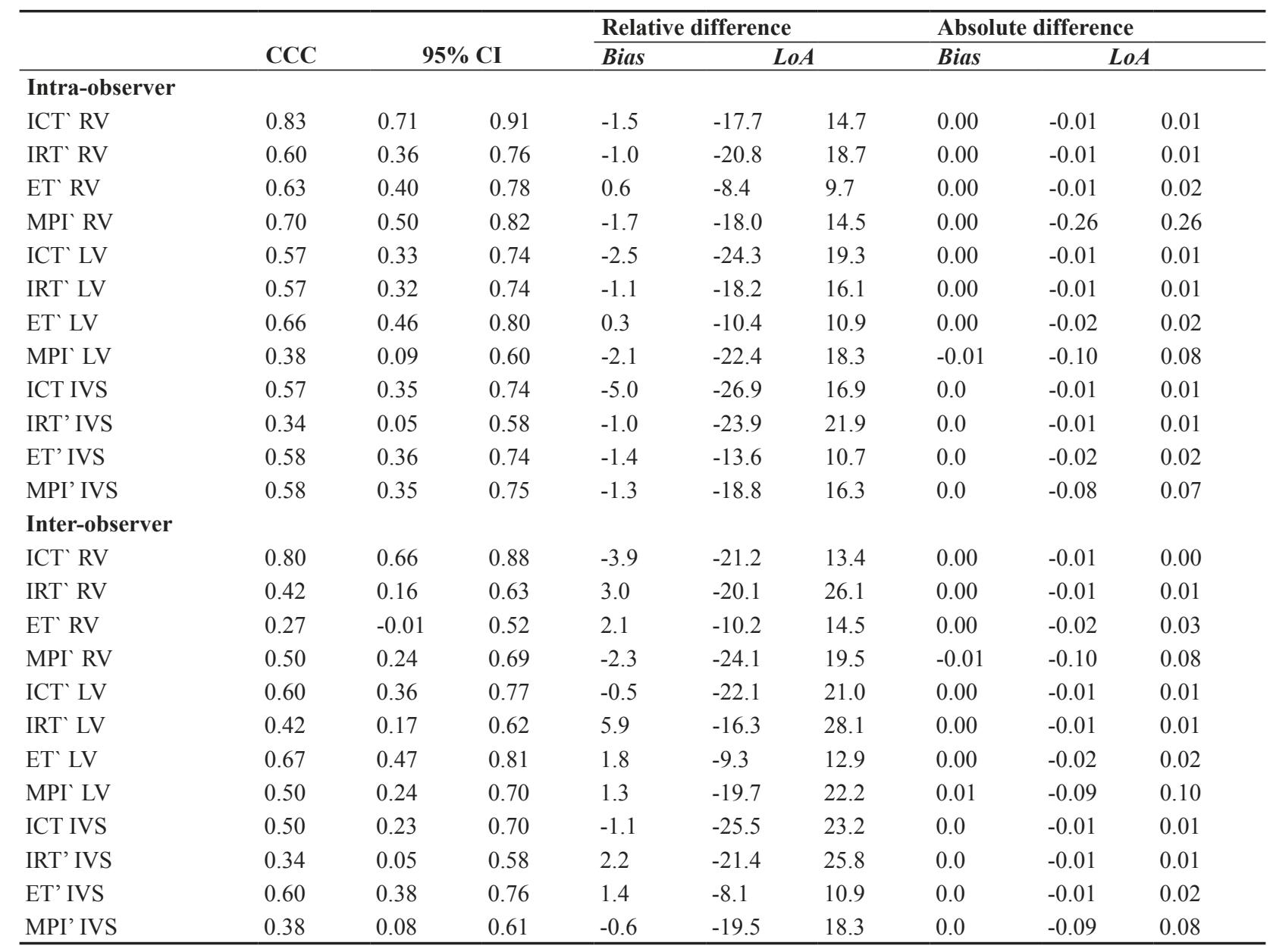

ET': ejection time using spectral tissue Doppler, ICT': isovolumetric contraction time using spectral tissue Doppler, IRT': isovolumetric relation time using spectral tissue Doppler, IVS: interventricular septum, LV: left ventricle, MPI': myocardial performance index using spectral tissue Doppler, RV: right ventricle.

et al study [9], we observed good-to-moderate intra-observer but low inter-observer agreement for RV MPI' values, with mean error percentages of $16.0 \%$ and $21.8 \%$, respectively. Concurrently, we observed low intra- and inter-observer agreement for LV MPI' values, as well as for most measures of the time intervals of $\mathrm{LV}$ and $\mathrm{RV}$ MPI'. Comas et al [26] analyzed intraclass correlation coefficients and have reported lower intra- and interobserver variability in RV MPI' measurements $(0.77$ vs. 0.70 and 0.70 vs. 0.50 , respectively) and LV MPI' values ( 0.79 vs. 0.38 and 0.78 vs. 0.50 , respectively) than those reported by us here.

The main positive attributes of our study are the presence of a representative sample that allowed determination of the reference values for TDI parameters and the use of the identical brands of ultrasound equipment with fixed ultrasound settings. Nonetheless, this study's limitations include low intra- and inter-observer reproducibility of MPI' values for both ventricles and IVS. Moreover, in clinical settings, the great variability between different ultrasound equipment decreases the value of the method. For research purposes, spectral myocardial tissue Doppler parameters would be applicable in the approach of some conditions during pregnancy such as: diabetes mellitus, fetal growth restriction, fetal anemia, twin pregnancies and congenital heart diseases.

In conclusion, we provide reference range values for MTD and MPI' and its respective time periods for between 20 and $36+6$ weeks of gestation. We believe that MTD should be employed for research purposes but with caution in clinical practice, whereas MPI' should only be used for research purposes. 


\section{Conflict of interest: none}

\section{References}

1. Comas M, Crispi F, Gomez O, Puerto B, Figueras F, Gratacós E. Gestational age- and estimated fetal weight-adjusted reference ranges for myocardial tissue Doppler indices at 24-41 weeks' gestation. Ultrasound Obstet Gynecol 2011;37:57-64.

2. Willruth A, Steinhard J, Enzensberger C, et al. Fetal colour tissue Doppler imaging (cTDI): biventricular reference ranges for the time segments of the cardiac cycle in second and third trimesters of gestation. Arch Gynecol Obstet 2016;294:917-924.

3. Cruz-Lemini M, Valenzuela-Alcaraz B, Figueras F, et al. Comparison of Two Different Ultrasound Systems for the Evaluation of Tissue Doppler Velocities in Fetuses. Fetal Diagn Ther 2016;40:35-40.

4. Chan LY, Fok WY, Wong JT, Yu CM, Leung TN, Lau TK. Reference charts of gestation-specific tissue Doppler imaging indices of systolic and diastolic functions in the normal fetal heart. Am Heart J 2005; 150:750-755.

5. Nii M, Roman KS, Kingdom J, Redington AN, Jaeggi ET. Assessment of the Evolution of Normal Fetal Diastolic Function During Mid and Late Gestation by Spectral Doppler Tissue Echocardiography. J Am Soc Echocardiogr 2006; 19:1431-1437.

6. Saini AP, Ural S, Pauliks LB. Quantitation of Fetal Heart Function With Tissue Doppler Velocity Imaging-Reference Values for Color Tissue Doppler Velocities and Comparison With Pulsed Wave Tissue Doppler Velocities. Artif Organs 2014;38:87-91.

7. Halpern DG, Sanchez-Ross M, Joshi S, Cantales D, Chaudhry FA, Sherrid MV. Discrepancies between tissue doppler velocities on different echocardiography machines: Comparing apples to oranges. Echocardiography. 2013;30:730-732.

8. Tei C, Ling LH, Hodge DO, et al. New index of combined systolic and diastolic myocardial performance: a simple and reproducible measure of cardiac function--a study in normals and dilated cardiomyopathy. J Cardiol 1995;26:357366.

9. Bui YK, Kipps AK, Brook MM, Moon-Grady AJ. Tissue doppler is more sensitive and reproducible than spectral pulsed-wave doppler for fetal right ventricle myocardial performance index determination in normal and diabetic pregnancies. J Am Soc Echocardiogr 2013;26:507-514.

10. Hernandez-Andrade E, Lopez-Tenorio J, Figueroa-Diesel $\mathrm{H}$, et al. A modified myocardial performance (Tei) index based on the use of valve clicks improves reproducibility of fetal left cardiac function assessment. Ultrasound Obstet Gynecol 2005;26:227-232.

11. Meriki N, Welsh AW. Development of Australian reference ranges for the left fetal modified myocardial performance index and the influence of caliper location on time interval measurement. Fetal DiagnTher 2012;32:87-95.

12. Duan Y, Harada K, Wu W, Ishii H, Takada G. Correlation between right ventricular Tei index by tissue Doppler imaging and pulsed Doppler imaging in fetuses. Pediatr Cardiol 2008;29:739-743.

13. American Institute of Ultrasound in Medicine. AIUM practice guideline for the performance of fetal echocardiography. J Ultrasound Med 2013;32:1067-1082.

14. International Society of Ultrasound in Obstetrics and Gynecology, Carvalho JS, Allan LD, et al. ISUOG Practice Guidelines (updated): sonographic screening examination of the fetal heart. Ultrasound Obstet Gynecol 2013;41:348359.

15. Royston P, Wright EM. How to construct "normal ranges" for fetal variables. Ultrasound Obstet Gynecol 1998;11:30-38.

16. Moore TR, Cayle JE. The amniotic fluid index in normal human pregnancy. Am J Obstet Gynecol 1990;162:11681173.

17. Hadlock FP, Harrist RB, Sharman RS, Deter RL, Park SK. Estimation of fetal weight with the use of head, body, and femur measurements - a prospective study. Am J Obstet Gynecol 1985; 151:333-337.

18. Nicolaides KH, Wright D, Syngelaki A, Wright A, Akolekar R. Fetal Medicine Foundation fetal and neonatal population weight charts. Ultrasound Obstet Gynecol 2018;52:44-51

19. Comas M, Crispi F. Assessment of fetal cardiac function using tissue doppler techniques. Fetal Diagn Ther 2012;32:30-38.

20. Crispi F, Valenzuela-Alcaraz B, Cruz-Lemini M, Gratacós E. Ultrasound assessment of fetal cardiac function. Australas J Ultrasound Med 2013;16:158-167.

21. Acharya G, Pavlovic M, Ewing L, Nollmann D, Leshko J, Huhta JC. Comparison between pulsed wave-Doppler and tissue Doppler-derived Tei indices in fetuses with and without congenital heart disease. Ultrasound Obstet Gynecol 2008;31:406-411.

22. Altman DG, Chitty LS. Charts of fetal size I: Methodology. Br J Obstet Gynaecol 1994;101:29-34.

23. Martins WP, Nastri CO. Interpreting reproducibility results for ultrasound measurements. Ultrasound Obstet Gynecol 2014:43:479-480

24. Gardiner HM, Pasquini L, Wolfenden J, et al. Myocardial tissue Doppler and long axis function in the fetal heart. Int J Cardiol 2006;113:39-47.

25. Arduini D, Rizzo G, Romanini C. Fetal cardiac output measurements in normal and pathologic states. In: Copel JA, Reed K1, editors. Doppler ultrasound in obstetrics and gynecology. New York: Raven Press; 1995:271-290.

26. Comas M, Crispi F, Cruz-Martinez R, Martinez JM, Figueras F, Gratacós E. Usefulness of myocardial tissue Doppler vs conventional echocardiography in the evaluation of cardiac dysfunction in early-onset intrauterine growth restriction. Am J Obstet Gynecol 2010;203:45.e1-e7. 